\title{
Article \\ From Ama Lur to the Anthropocene and Back: The Earth in Basque Mythology
}

\author{
Luis Garagalza
}

Department of Philosophy, University of the Basque Country, 48940 Leioa, Spain; luis.garagalza@ehu.eus

\begin{abstract}
What I propose is that, by delving into the world of mythologies, there we might find some indications, helpful for understanding what is happening with the environment today. To do so, I will revisit a particular mythology from the South of Europe, an archaic (probably, a pre-Indo-European one), namely Basque mythology. Here, earth (lurra) appears as a maternal character (Ama-lur) and becomes, in a sense, divine in the figure of the goddess Mari, who occupied a central and predominant position in this cosmovision.
\end{abstract}

Keywords: mythology; goddess; earth; environment

\section{Introduction: A New World or the Rise of Worldlessness}

The twentieth century bid us farewell with the image of the fall of the Berlin wall, announcing the end of the Cold War. With it, the main enemy, too, disappeared, the enemy used to justify and ideologically legitimate multiple defects in the capitalist system. As a concrete enemy dissolved-against whom ideological masks were created, presenting themselves as the Truth-so did these masks themselves. So much so, that it now appears that the very necessity and pretense of truth has become obsolete, and we have entered the realm of post-truth.

The twenty-first century arrived unannounced with the attack on the Twin Towers that shook the world to its foundations, forcing us to consider whether we have not forgotten evil [1]. The vision of the tumbling towers moved us, as though it were a premonition of the fate reserved for our world, a catastrophe toward which we are marching almost mechanically, unless we manage to change our way of life, of feeling and thinking, both individually and collectively. This image of the crumbling towers has become associated with the atomic mushroom cloud growing sky-high, and has invited us to realize that, if we fail to change, our civilization will head like a sleepwalker to its own destruction.

Another image that has been engrained in our minds with the arrival of the twenty-first century is that of a network, which has dramatically transformed our mode of communication. The influence of the Internet on our lives, with its extension through mobile phones, is enormous: it has triggered a global transformation. McLuhan lived in a pre-Internet era, but he intuited that the medium was the message. The vertiginous development of a new medium brings us the message that the new world, in which we continually discover how our old world is becoming obsolete, is itself already crumbling. The new network that virtually connects us is reminiscent of the old "world soul" that put everything in touch, and that mediated between the material world and spiritual or divine otherworldliness. Now, the other world is no longer simply an ideal, but a purely intelligible reality: the virtual reality of cyberspace.

We are living, therefore, in a strange and enigmatic world (and it is not at all clear that it is still or already a world), disquieting and fear-inducing, one which we could qualify as "terrible", deinon, a word that the chorus in Sophocles' Antigone uses to refer to human beings. It seems as though today the world itself is coming undone and, in its undoing, affects the earth, into which its toxic residues penetrate, without sparing terrestrial entrails,

Copyright: (c) 2022 by the author Licensee MDPI, Basel, Switzerland. This article is an open access article distributed under the terms and conditions of the Creative Commons Attribution (CC BY) license (https:// mons.org/licenses/by/ 
the atmosphere, or the deepest parts of the ocean. In order to approach our current situation and to try to comprehend it as deinon, we may resort to the term Anthropocene, coined by Paul Crutzen. According to this winner of the Nobel Prize in Chemistry, the scope of human action has acquired such magnitude that one may detect its effects in the strata of the earth with the help of geological sciences. As a result, as the Work Group on the Anthropocene confirmed in 2016 at the International Congress of Geology in South Africa, we are living through a change of geological era and entering a new epoch.

\section{Anthropocene and the Earth}

The word Anthropocene, which etymologically means "a new or recent human being", arrives at a moment of generalized crisis in nearly all the spheres of our lives, and appears to signal nothing less than an epochal shift: we are leaving the Holocene (meaning "all new or recent"), which started around 11,000 years ago with climate change that unfolded after the last ice age, and entering another epoch, similarly marked by climate change, though the current one appears to have been caused by humans.

In the Anthropocene, humans have domesticated the world, converting nature into something like their own home and appropriating the environment. Now, humans cease to be a mostly insignificant part of nature, and discover that they are the main actors, the protagonists of a drama that affects nature as a whole. The fear and impotence that we suppose dominated the lives of our ancestors are left far behind, thanks to the scientific and technological resources acquired in modernity.

We are no longer at the mercy of natural cycles, having transformed ourselves from the guests to the owners of the planet, and having marked all its territory as "ours." Even the deepest parts of the ocean bear our marks. The earth is our home. The desire that the Faustinian subject of modernity formulated-namely, to shine the light of knowledge everywhere-appears to have been fulfilled once and for all. Like Midas, who converted into gold everything he touched, we "humanize" everything that surrounds us, in the sense of adjusting it to our measure. However, in the same moment, when it seems that we have turned the earth into our home, we begin to suspect that it is no longer habitable, that it is not as strong as stone, and that it cannot absorb all the consequences of human behavior. There are evident symptoms of its fragility. We have pretended to control nature to such an extent, to domesticate it to such an extent, that it now becomes almost uncontrollable and uninhabitable.

In the past, we projected onto nature an image of an enemy that was much more powerful than ourselves, and that could not suffer any harm at our hands. All we could do was defend ourselves and await the day when we could assert our dominion over it. Nowadays, a different paradigm emerges: nature is no longer invincible, nor is it an external enemy, but that which involves us all and penetrates us when we breathe, eat, or drink. It is no longer only outside, but inside and outside at the same time.

Assailed by ignorance, fear, and greed, we have not seen in nature anything other than an "external scenery" for our disputes, conflicts of interests and wars for world domination. No war-neither that of a military nor of an economic nor ideological variety-has attained this last goal, and yet the "scenery," which one deems to be alien, exterior and indifferent to human matters, has always insinuated itself into all of them. While we have not yet consolidated a social contract to guarantee peaceful coexistence among humans (rather than the operations of containment, struggling against infinite violence), the necessity of an amplified natural contract imposes itself upon us [2].

The environment is precisely that which modernity has left nearly forgotten in the background, as the background, as something which one cannot know, and which escapes our categories as if it did not exist. So, it is this almost inexistent (from the standpoint of the objectivating consciousness that prevails in modernity) thing that returns in the Anthropocene. Physis, which was a cause of wonder that awoke philosophical disquietude in Greece, now comes back, making us uneasy in a diffuse way. 
At the same time, the Anthropocene reminds us that the type of knowledge attained in modernity presupposes from the get-go that the subject and the object have always been already separated, while ignoring the process of separation, as though these were simply two completely distinct substances (res cogitans and res extensa) that, while they could be together, would never combine and intermingle (oil and water are evocative of this curious relation). In the measure that it is debunked, this presupposition reminds us of the very thing that the Anthropocene shows, namely a radical interconnection between humanity and the planet. The impact of our activity on the environment is of such magnitude that we have left our contaminating imprint over the whole earth.

The presupposition of a separation between the subject and the object, which we might call "a dualist prejudice", on which rests to a great extent all of modernity, may be studied from a perspective of the history of mythologies. In fact, the mythological name of the goddess Gea-Gaia was proposed by Lovelock and Margulis in the 1980s as the name for a hypothesis, according to which the biosphere behaved as an interactive and self-regulating system. Though opposed to this hypothesis, Latour keeps its mythological name with the intention of rethinking, of putting into question the presumed dichotomy subject/object and, in general, all the dichotomies between opposites (the mind and the body, reason and sensibility, form and matter, concept and image, analysis and synthesis, mythos and logos, the feminine and the masculine, etc.) [3]. Neuropsychology is also suggesting something similar [4]:

"I assume that dualist thought emanates from the characteristic of the brain that sensitizes it to contrasts, rather than to absolutes. So, if we are conscious of the fact that this form of thinking is not the only one and that it is more an instrument for analyzing reality by our brain than a feature of that reality itself, we will not fall into the trap of considering nature as dualist, or, worse still, of accepting entrenched divisions that, according to ideologies, reflect reality-something that has had historically nefarious consequences" [4].

On the other hand, the history of philosophy also gives us clues concerning the issue. We should keep in mind, as Ortiz-Osés does, the connection between a metaphysical conception of the real as being and Greek language, in which this conception is brewing, as well as the anthropological experience that sustains it [5]:

"This vision of the real as an entity or object envisioned by a subject is manifest in Greek, an Indo-European language, whose structure permits the subject to predicate all that 'is' (being). This is something that cannot be accomplished in other languages, which do not have the substantivating copula 'is', but which speak of things as events (for example, 'the green greens')" [5] (pp. 199).

As Gaia returns in the Anthropocene, it thrusts us into a sort of confusion, an entanglement. The return of Gaia is, however, not literal. She does not appear on the scene, but, in some way, talks to us and generates images. Her figure insinuates itself indirectly, as notes I. Stengers, through symptoms or symbols [6]:

"For Lovelock and Margulis, who are respectable if slightly heretic scientists, Gaia is there before everything to tell us about the antiquity of life, the thousands of millions of years during which myriads of bacteria literally fabricated the earth which we inhabit. Gaia stresses the indissociable connection between this ancient multitude of living beings, the climatic regimes under which we are living, the very existence of the oceans and fertile soil. All of a sudden, nature is there and what it produces is the piling up (enchevêtrement: entanglement, confusion) of what we could previously distinguish".

It seems like Gaia comes to complicate things for us, to confound and entangle us. It is as if she wanted to ask us not to limit ourselves to thinking in dualist schemes that have reigned in Western culture and philosophy. She prompts us to try to explore other possibilities, perhaps at the price of clarity and distinction, which Descartes greatly 
appreciated. In another, stronger sense, she asks that we do not limit ourselves to thinking, that we do not use only the intellect, that we open other possible approaches ignored by our culture. It is as though she wanted to remind us of the lost wisdom of the pre-Socratics, who attended to the co-implication of opposites in life ("a life lived as a mystery from birth to death", according to Heraclitus). This old wisdom uncovers a vision of the world in which the real presents itself as a constant transformation, and opposites are conceived of as inseparable moments that pertain to the same continuous movement and that have a common origin.

In the footsteps of these general considerations about the so-called Anthropocene and the return of Gea-Gaia, what I propose is to go beyond this old wisdom, to which I have alluded, delving into the world of mythologies in order to see whether there we might find some indications that could be helpful in understanding what is happening today. To do so, I will revisit a particular mythology from the South of Europe, a very archaic (probably, a pre-Indo-European one), namely Basque mythology. Here, earth (lurra) appears as a maternal character (Ama-lur) and becomes, in a sense, divine in the figure of the goddess Mari, who occupied a central and predominant position in this cosmovision. I do not wish, obviously, to idealize or to idolatrize this cosmovision as a part of a past golden age, a paradise which we lost and would wish to return to. Rather, I would like to pay close attention to this matriarchal, maternal earth in order to assess whether it could be a counterpoint, from which to become conscious of the patriarchal myth, on which our mode of relating to the earth and to ourselves relies, and to liberate ourselves from this kind of myth. Mine will be a critical recourse to Mother Earth, meant to "deconstruct" the dominant patriarchal discourse or cosmovision and open fissures in it, fissures through which our longing for sense and our desire for a new mode of fraternal or fratriarchal relation with the cosmos and with ourselves could be expressed.

\section{The Earth in Basque Mythology (Ama-Lur)}

This theme unites myths, stories and legends that have been preserved by the oral tradition and recompiled in the first half of the twentieth century, above all, by José Miguel de Barandiarán, who has saved them from oblivion. The anthropologist Julio C. Baroja initiated the interpretation of the materials collected by Barandiarán and A. Ortiz-Osés, and made an exhaustive reading of it applying the symbolic hermeneutics of Jung and his associates of the Eranos Circle [7]. Much like the Basque language (Euskera), Basque mythology displays a pre-Indo-European character: it is a modality of paganism that preceded the arrival of Christianity and that contains a vision of the world connected to the matriarcho-feminine mythologies of what archeologist Marija Gimbutas called “Old Europe" [8].

When Barandiarán began to study this paganism, which was still present in a more or less diffuse way in rural society and in the mentality of the Basque people, he was surprised by the fact that a large share of the information he received was linked to the figure Mari, whom he called "the spirit of the mountains" and whom he considered to be an "extraordinary being", recognizing in her, if only as a hypothesis, "a divinity of the old religion of the Basques" [9] (p. 272).

In this way, Barandiarán detected what might be considered as the principal characteristic of Basque mythology, notably that its vision of the world pivoted symbolically on the figure of Mari, intimately connected with the earth. In order to adequately understand this character, it is imperative to interpret it, as I will try to demonstrate shortly, as one of the representations of the Great Goddess, who, since Prehistory, has presided over and promoted the cultural, symbolic, and linguistic development of humanity. Let us allow Gimbutas to present to us the Goddess of Old Europe, whose innumerable images display a conception of life and nature as a process of constant transformation, change, and becoming, a rhythmic oscillation between creation and destruction, birth and death, as an unstoppable movement, in which opposites are interrelated in the circularity of regeneration [10]: 
"The main themes represented in the symbolism of the Goddess are the mystery of birth and death, as well as of the renewal of life, not only on the human plane, but also on that of the planet, and, of course, of the cosmos. Symbols and images are gathered around the parthenogenic (self-generating) Goddess and her basic functions as the Giver of Life or the Carrier of Death and as the regenerator of Mother Earth. She was the only source of life, which drew its energy from water springs and wells, from the sun, from the moon and humid earth. This complex of symbols points at mythic time, which is cyclical, not linear. In art, this is manifest in signs-in-motion: spirals that curve and gyrate, rolled and meandering serpents, circles, crescents, bull horns, germinating seeds and shoots. The serpent was in this context the symbol of vital energy and regeneration, a creature that was most benevolent, not evil" [10] (p. XIX).

This conception of nature, of the earth, and of life as configured in the symbolism of the Goddess stand in sharp contrast, as Campbell notes, with the one presented in the Bible, when in Genesis 3:19, the Creator tells Adam: "With the sweat of your brow shall you eat your bread until you return to the earth, from which you were taken: dust you were and dust you shall become" [11]. From the standpoint of the Goddess, the earth is not dust, but life, living matter that in its incessant movement generates and regenerates everything. Moreover, there, the serpent is not the target of the Lord's wrath ("you shall be damned among all the animals and creatures of the earth: on your belly shall you drag yourself and earth you shall eat all the days of your life"), but is the symbol par excellence of the matriarcho-feminine mystery of regeneration. The serpent is associated with motifs that symbolize water and vital humidity, such as spirals, zigzags, meanders, labyrinths, etc., that profusely decorate the statues and ceramic pieces throughout the Neolithic period. According to Gimbutas, these might be allusions and offerings, with which humanity attempted to collaborate symbolically, assisting in the fundamental task of sustaining life and ensuring its cyclical return and rejuvenation [12].

Now, Basque mythology shares with the majority of traditional cultures a geocentric vision of the cosmos, in which the earth is beneath, supporting us, while the firmament is above, full of celestial bodies that move, rotating and revolving around it (and around us, given that we are in the center of cosmos) in perfectly circular orbits (save for the anomalous case of the planets).

This traditional vision is in contrast to the scientific conception, established by Galileo and Newton, according to which the earth moves around the sun. The sun is no longer, as it still appears to us to be, the biggest and most powerful star, but a medium-sized one, like billions of other stars. It turns out, also, that the earth recognizes the dignity of celestial bodies, but at the price of its central position: neither it nor we, ourselves, are in the center of the universe, but in some corner of a small galaxy lost in the immensity of the cosmic night.

For traditional mentality, which keeps close to the evidence of ancient experience, the sun naturally, sensorially, and symbolically comes every morning out of the interiority of the earth, or according to geographic orientation, of the sea, which takes care not to extinguish it. Although we all know perfectly well that it is only an appearance, everyone, including physicists, continues to say that the sun comes out at dawn and sets or goes down at dusk. In the Basque case, moreover, it is believed that the sun and the moon-both of them in the feminine and related to one another as sisters-are the daughters of the earth that emerge from and return to her, passing through her interiority in order to be reborn, regenerated the next day. The earth is, thereby, conceived as Mother (Ama Lur), which is why a cult forms around her figure and offerings are made. She also has a cosmic character, since, from below, in a sort of unlimited embrace, she encompasses everything: the mineral, the vegetal, the animal, the human, stars, and even the sky (Urtzi) itself, as her extreme limit. One could say, in consequence, that Basque mythology contains a telluric or terrestrial cosmovision, in which the earth represents the body of the universe, the mother and matter of which all beings are constituted, including the human (likewise, in Latin, the 
etymology of human-homo-is humus, which means the earth). In this respect, it might be worthwhile to establish a mytho-symbolic connection between Basque culture and Minoan (Cretan) culture, as A. Ortiz-Osés has done [13]. Both pertain to the ambit of what we have called Old Europe. Curiously, in Basque language (euskera), the word that means "matter," whether in the sense of materials used to make something or in the sense of a subject of conversation is gaia, coinciding with the name of the Greek earth goddess (Gea-Gaia).

\section{Animism in Basque Mythology}

This body of the universe that is the earth has an interior part, considered valuable and sacred: through its tunnels, travel the stars, mysterious forces and magic being; it also contains treasures, such as gold, fire, water, rivers of milk and honey, etc. Furthermore, it has a profane exterior portion, which we inhabit and upon which our everyday life circulates. However, if the earth is the body of the universe, the goddess Mari-the symbol and personification of the forces and energies that traverse the cosmos and human beingswould represent its soul.

In this case, the soul is not aethereal; it does not aspire to ascend on high, but keeps close to concrete places, dwelling in them and sporadically surfacing through various forms in order to animate, reanimate, compensate or balance out the course both of natural processes (rain and drought, for example) and of the psycho-social life of a community. Mari appears in this sense as the personification of the soul of the earth, as mysterious vital energy, symbolized by gold and fire kept in her entrails-the soul that animates the earth from within, converting it into a living being and giving life to all the things that spring from it, while maintaining them as interconnected by relations of correspondence based on sympathy and repulsion, or love and hate.

Thus, we are witnessing a worldview, which has been called hylozoic (derived from the Greek hylé, matter, and zoé, life) and which is one of the variants of animism, characteristic of a magic mindset. In animism, nature is viewed as animated, as if it were a living being. Here, there is no distinction between purely mechanical regularity and psychic motivation: all things behave as living, as endowed with intentions and pursuing determinate ends.

Still one of the first Greek philosophers, Thales of Miletus, affirmed that "everything came from water" and that "everything was full of gods" (and even for a philosopher as scientific as Aristotle, a stone falls because the natural place of heavy things is below, and they "want" or have it as their end to return to their place). This worldview actually continues to exist, even if it is under siege laid by the predominant techno-mechanical outlook, which obsessively strives to the maximization of efficiency. It is, for example, possible to detect the traces of this half-repressed worldview in what, before the rise of ecological consciousness, Max Scheler called "affective fusion" with nature; in the thesis formulated by Teilhard de Chardin that the cosmos could not have harbored human beings unless matter had "psychic texture"; or, within Basque culture, in the "cosmovital sentiment" that, according to Juan Thalamas, an expert in popular Basque mentality, inspired and impregnated the poetry of Lizardi.

In the animist context, what is experienced as real is, precisely, the influence or the influx of things over human beings: there is no clear distinction here between subjectivity and objectivity, nor between things and the effects they produce in whoever perceives them. The image and the name belong to the thing and are identified with it. That is why the first ethnologists were met with resistance when they attempted to photograph indigenous people, who believed that if someone kept their image, they would appropriate their soul and acquire power over them.

In the same context, the traditional Basque saying, "everything that has a name is said to be" (izena den guztia omen da) makes sense. To be sure, this does not hold water in the world of mechanicist objectivity, but in that of contemporary philosophical hermeneutics, according to which language articulates the human experience of reality, such that a name expresses an interaction between reality and human being, who, by saying it, configures and interprets it as such. Accordingly, the name names a relation between the thing and 
the one who lives in contact with it, the influx or the influence that the real wields over human beings.

Through this observation, we may discover a sort of alliance between contemporary hermeneutic philosophy, represented by Heidegger and Gadamer, and archaic animist mentality, which is preserved in Basque mythology [14] (pp. 567). Both differ from the mechanicist worldview adopted by Newtonian physics, predominant in modernity, the worldview that only considers as real that which can be conceived and explained by assuming that the machine (above all, a clock) is a metaphor for reality. Contrary to this metaphor, animist mentality offers a dynamic, energetic vision of reality that is in a constant process of realization through symbolism, language, a vitalizing and humanizing interpretation.

\section{Back to the Anthropocene with the Old-New Energies of Basque Mythology}

Although it is a term that has cropped up in geology, the word Anthropocene also carries a significant symbolic charge. Like everything that is human, the Anthropocene not only alludes to an event, but is a symbol; it symbolizes something. Besides saying (or permitting us to say) something in particular, it means to say something-probably, many things. We would thus have to listen to the word, let it resonate with its symbolism within us, in order to interpret the meaning and the meaningless of what is happening to us.

As a symbol, the Anthropocene requires our interpretation: without such an interpretation, its meaning and meaningless get enmeshed, fused, and confused. It also requires that we consider it attentively, meditating without thinking of anything, without saying anything, without judging it. Interpretation and mediation are necessary so that we would be able to take on what is happening to us, including the sense and nonsense of the event, its promises and threats, our fears and our hopes. Because the Anthropocene is upon us with all its ambivalence, as something demonic, provoking fascination and terror at one and the same time [15].

On the one hand, the Anthropocene fascinates us because it brings with it a global change of our values, of our sciences, arts, and technologies, of our ways of life, of perception and thinking. Perhaps, it would be possible, or even necessary, as J. Hillman points out in the footsteps of a long tradition, to reimagine psychology, to go back to imagining imagination itself (just as Heidegger proposed to poeticize the essence of poetry) so that imagination would again imagine us, ourselves, and the world [16].

However, on the other hand, the Anthropocene is upon us with a feeling of terror, given the possibility of global destruction, for which humanity now has all the necessary means (and it is not so sure that we have gained the wisdom and the prudence to avoid it). Therefore, complexio oppositorum might be one of the most fundamental characteristics of the Anthropocene, the daimon of the Anthropocene. Humanity has attained a global presence. Therein, its power is rooted. However, it lacks the potency to listen to the creative force of life, the soul of the world and sophia that are fleshed out in a search for meaning, including in its ancient Basque instantiation. Now we know that we have "sold" the soul, and that this has also led to a loss of spirit, which, without being anchored in the soul, has also been transformed into a mechanism, reduced to a mere instrument at the behest of the new power that the modern subject has drawn from its enclosure in a magic lamp: the economic power in its most abstract manifestation, namely, the financial one.

Far from witnessing the triumph of truth, the rise of the Anthropocene announces itself as the rise of an era of post-truth. What I propose is that we assume our failure, that we stop fooling ourselves with the idea that optimism and a positive attitude are capable of protecting us against all evils, including those of History. We ought to stop believing that our failure has not been definitive, that, should we keep working with renewed enthusiasm and dedication, we would score a final victory.

I am not talking about a victory that has been delayed, but of a renunciation of the very perspective of victory. To assume defeat and failure, to assume our weakness, our imperfection, our defects and lacks, among other obscurities-this will not yield a heroic attitude, but it might humanize us in a way different from the one in which we 
"humanize" the planet in the Anthropocene. To humanize oneself may be understood as a process of "soul-making" (Keats), as the acceptance of the soul's perspective with its daimonic character, evident in the goddess Mari, as an intermediary between body and spirit, engaged in a search for meaning. In fact, this "search for meaning" is marked by inter-mediacy, in which the co-implication of opposites is governed by the way of vegetal life. Thus, according to M. Marder, plants grow "in the middle," between earth and sky [15].

However, it turns out that in this search for meaning, the one who seeks it is already embroiled (perhaps, in a fraterno-fratriarchal mode?) with the meaning that is sought (for, if it were not so, how could one seek it?) and, on the contrary, that the meaning being sought is implied in the search itself, because the search for meaning, just as a journey to Ithaca, which Kavafis poeticized, already has a certain meaning. In this sense, the search appears as a symbol of the mutual implication of opposites, holding the keys of life and of death. The search for meaning happens almost always on the margins of what is signified, and is not exposed in bright light. As Luis Rosales says poetically, "in the night we go, in the night, since, as we look for the source, only thirst will illuminate our path" [17]. It is an obscure, daimonic light that helps us in this search, one which may be understood as the philosophy of the sense of the earth and an affirmation of life, resonating with ancient Basque mythology.

Funding: This research received no external funding.

Institutional Review Board Statement: Not applicable.

Informed Consent Statement: Not applicable.

Data Availability Statement: Not applicable.

Conflicts of Interest: The author declares not conflict of interest.

\section{References}

1. Dupuy, J.-P. Avions-Nous Oublié Le Mal? Penser La Politique Après Le 11 Septembre; Bayard: Paris, France, 2002.

2. Serres, M. El Contrato Natural; Pre-Textos: Valencia, Spain, 1991.

3. Si tu Viens à Perdre la Terre, à Quoi te Sers D'avoir Sauvé ton Âme? Available online: http://www.bruno-latour.fr/sites/default/ files/109-ECOTHEO-FR.pdf (accessed on 12 March 2020).

4. Rubia, F.J. Available online: https://www.tendencias21.net/El-dualismo-seria-una-categoria-mas-de-nues-tra-mente_a3438. html (accessed on 2 May 2019).

5. Ortiz-Osés, A. Metafísica del Sentido; Universidad de Deusto: Bilbao, Spain, 1989.

6. Stengers, I. Faire Avec Gaïa: Pour Une Culture de la Non-Symetrie. Available online: http://www.multitudes.net/wp-content/ uploads/2006/04/24-stengers.pdf (accessed on 5 July 2018).

7. Ortiz-Osés, A. El Inconsciente Colectivo Vasco; Txertoa: San Sebastián, Spain, 1982.

8. Gimbutas, M. Diosas y Dioses de La Vieja Europa; Siruela: Madrid, Spain, 2014.

9. Barandiarán, J.M. Obras Completas; La Gran Enciclopedia Vasca: Bilbao, Spain, 1972; Volume I.

10. Gimbutas, M. El Lenguaje de la Diosa; Dove: Madrid, Spain, 1996; p. XIX.

11. Campbell, J. Las Máscaras de Dios: Mitología Occidental; Alianza Editorial: Madrid, Spain, 1992.

12. Gimbutas, M. Diosas y Dioses de la Vieja Europa; Ediciones Istmo: Madrid, Spain, 1991.

13. Ortiz-Osés, A. La Diosa Madre; Trotta: Madrid, Spain, 1996.

14. Gadamer, H.G. Verdad y Método; Sígueme: Salamanca, Spain, 1977; p. 567.

15. Ortiz-Osés, A.; Garagalza, L. Lo Demónico. El Duende y el Daimon; Anthropos: Barcelona, Spain, 2019.

16. Hillman, J. Re-Imaginar la Psicología; Siruela: Madrid, Spain, 1999.

17. Luis Rosales Nuevo Retablo de Navidad. About the Relation of the Night and Silence D'Ors, P. In Biografía del Silencio; Siruela: Madrid, Spain, 2012. 